\title{
Black Mesoporous Silicon as a Contrast Agent for LED-Based 3D Photoacoustic Tomography
}

\author{
Wujun Xu, Jarkko Leskinen, Jenni Tick, Emilia Happonen, Tanja Tarvainen, and Vesa-Pekka Lehto*
}

Cite This: ACS Appl. Mater. Interfaces 2020, 12, 5456-5461

Read Online

ABSTRACT: Mesoporous silicon (PSi) nanoparticles have been widely studied in different biomedical imaging modalities due to their several beneficial material properties. However, they have not been found to be suitable for photoacoustic imaging due to their poor photothermal conversion performance. In the present study, biodegradable black mesoporous silicon (BPSi) nanoparticles with strong light absorbance were developed as superior image contrast agents for photoacoustic tomography (PAT), which was realized with a light-emitting diode (LED) instead of the commonly used laser. LED-based PAT offers the advantages of low cost, compactness, good mobility, and easy operation as compared to the traditional laser-

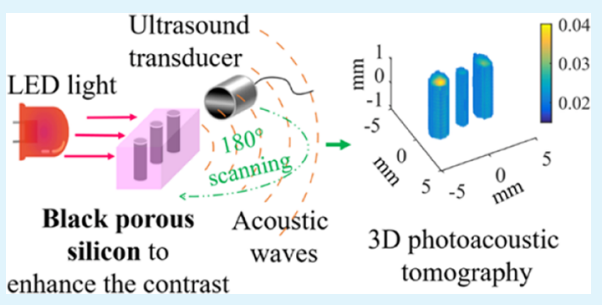
based PAT modality. Nevertheless, the poor imaging sensitivity of the LED-PAT systems has been the main barrier to prevent their wide biomedical application because the LED light has low optical energy. The present study demonstrated that the imaging sensitivity of the LED-PAT system was significantly enhanced with the PEGylated BPSi (PEG-BPSi) nanoparticles. The PEG-BPSi nanoparticles were clearly detectable with a low concentration of $0.05 \mathrm{mg} / \mathrm{mL}$ in vitro and with an LED radiation energy of $5.2 \mu \mathrm{J}$. The required concentration of the PEG-BPSi nanoparticles was 10 times lesser than that of the reference gold nanoparticles to reach the corresponding level of the imaging contrast. The ex vivo studies demonstrated that the submillimeter BPSi nanoparticlebased absorbers were distinguishable in chicken breast tissues. The strong contrast provided by the BPSi particles indicated that these particles can be utilized as novel contrast agents in PAT, especially in LED-based systems with low light intensity.

KEYWORDS: silicon nanoparticles, porous materials, photothermal conversion, imaging contrast, sensitivity, photoacoustic imaging

\section{INTRODUCTION}

Photoacoustic tomography (PAT) has lately been investigated as one of the most promising photonic imaging and diagnostic modalities. ${ }^{1-3}$ Unlike other optical imaging modalities, PAT converts light into ultrasound via thermoelastic expansion, and the generated ultrasound signal is monitored for imaging. Thus, PAT integrates the unique optical contrast and the high spatial resolution of ultrasound. ${ }^{4,5}$ A wide range of nanomaterials such as organic dye nanoparticles, ${ }^{6-8}$ gold nanoparticles, ${ }^{9-11}$ carbon nanotubes, ${ }^{12}$ and copper sulfide $^{13,14}$ nanoparticles have been extensively studied as potential contrast agents for PAT imaging due to their strong photothermal conversion effect. However, each of these nanomaterials has its own disadvantages. For instance, organic dyes usually encounter the issue of poor photostability. ${ }^{15}$ Inorganic gold and carbon nanoparticles have a very slow biodegradation rate. Copper sulfide increases the risk of heavymetal accumulation in the body. In general, the nanomaterials used in vivo should be biodegradable and safe. ${ }^{16}$

Mesoporous silicon (PSi) nanoparticles have a high surface area, large pore volume, and good biocompatibility. ${ }^{17,18}$ The degradation product of porous silicon is orthosilicic acid, which is nontoxic and is essential for optimal bone and collagen growth. ${ }^{19}$ They have been widely studied in different biomedical imaging systems like in fluorescence ${ }^{18}$ and ultrasound imaging. ${ }^{19}$ Even though there are some recent studies on the development of the photoacoustic imaging contrast agents based on PSi, ${ }^{20,21}$ PSi nanoparticles have only been utilized as carriers for different contrast agents such as indocyanine green $^{20}$ and carbon nanomaterials. ${ }^{21}$ In these studies, PSi itself did not play any functional role in the imaging due to its poor light absorption performance. To the best of our knowledge, there are no studies published on the PAT contrast agents solely based on PSi nanoparticles. In our previous study, ${ }^{22}$ a new type of black mesoporous silicon (BPSi) nanoparticles was developed via the chemical oxidation method. The BPSi nanoparticles possessed better photothermal performance than gold nanoparticles, carbon nanotubes, and $\mathrm{Fe}_{3} \mathrm{O}_{4}{ }^{22}$ which have widely been studied as contrast agents in photoacoustic imaging. ${ }^{10,12,23}$ Therefore, due to their outstanding photothermal performance, we hypothesize that the BPSi nanoparticles can serve as novel contrast agents to enhance the imaging sensitivity of PAT.

Received: October 18, 2019

Accepted: January 10, 2020

Published: January 10, 2020 

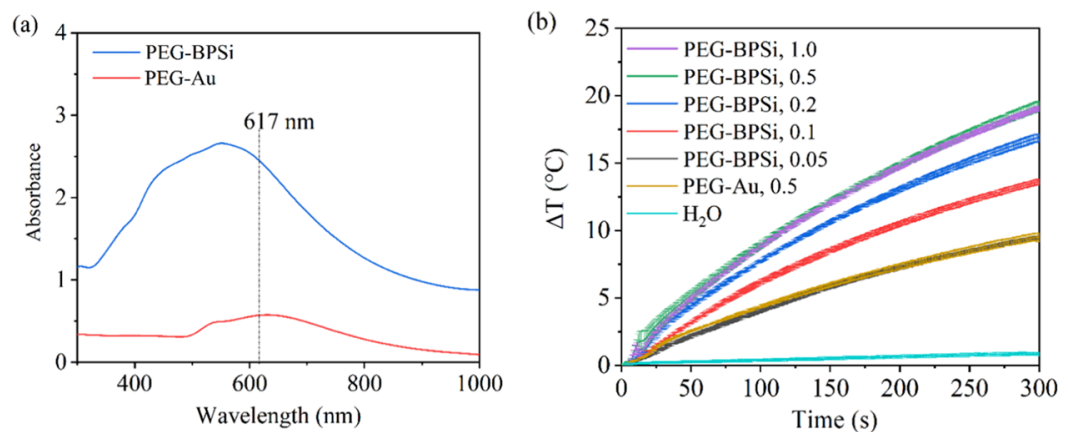

Figure 1. (a) UV-vis spectra of PEG-BPSi and PEG-Au nanoparticles at a concentration of $0.1 \mathrm{mg} / \mathrm{mL}$. The light source in the LED-PAT system has a wavelength of $617 \mathrm{~nm}$. (b) Heating curves of PEG-BPSi and PEG-Au nanoparticles with different concentrations under the illumination of LED (mean \pm standard deviation (SD), $n=3$ ). The concentrations of PEG-BPSi were $1.0,0.5,0.2,0.1$, and $0.05 \mathrm{mg} / \mathrm{mL}$. The concentration of PEG-Au was $0.5 \mathrm{mg} / \mathrm{mL}$.

Until now, PAT systems have been commonly based on the light source of class-IV lasers such as Nd:YAG lasers. ${ }^{25}$ Although these lasers can meet the demands of PAT, they are bulky, expensive, poorly movable, and suffer from energy fluctuations. LEDs have the advantages of compactness, low cost, good mobility, and stable light sources. ${ }^{26-29}$ Moreover, LED light can be easily operated in a typical indoor environment, while special safety restrictions and requirements (e.g., light shielding and water cooling) are necessary for the operation of the laser-based PAT. ${ }^{25}$ Nevertheless, due to the much weaker optical energy of the LEDs $(\mu \mathrm{J})$ than traditional lasers $(\mathrm{mJ})$, the poor imaging sensitivity is the main issue in the current LED-PAT system. The development of exogenous image contrast agents is an effective way to overcome such technical barriers. Up till now, a few contrast agents such as free organic dyes have been tested to enhance the imaging sensitivity of LED-PAT. ${ }^{28}$ The dye molecules were dissolved in a suitable solvent and then used as the contrast agent directly. However, even though different nanoparticles have been studied as the contrast agents in laser-based PAT, ${ }^{15}$ the application of nanoparticles as the contrast agent of LED-PAT has been rarely investigated. The aim of the present study is to develop novel contrast agents for PAT based on BPSi nanoparticles. These particles could provide a new way to overcome the challenge in the imaging sensitivity of LED-PAT. Tomographic imaging was performed with the prototype of the LED-PAT system. ${ }^{25}$

\section{RESULTS AND DISCUSSION}

The Raman scattering peak of silicon from the BPSi sample was observed at $515.6 \mathrm{~cm}^{-1}$. Compared with the Raman peak of $521.5 \mathrm{~cm}^{-1}$ for the silicon wafer, there was a clear blue shift attributed to the nanocrystalline structure of silicon in BPSi (Figure S1, Supporting information). The average size of the $\mathrm{Si}$ clusters was about $4.2 \mathrm{~nm} .{ }^{30}$ Two poly(ethylene glycol) (PEG) molecules with different lengths of the carbon chains (molecular weights 0.5 and $2.0 \mathrm{kDa}$ ) were conjugated on the surface of BPSi (PEG-BPSi). According to our previous study, the dual-PEGylation with two PEGs was more efficient to enhance the colloidal stability of the nanoparticles for biomedical applications than the common mono-PEGyaltion. ${ }^{24}$ The colloidal stability of the nanoparticles before and after the PEGylation was studied in PBS at $37^{\circ} \mathrm{C}$. The BPSi nanoparticles without PEGylation aggregated quickly, and the particle diameter increased to 1.0 and $4.0 \mu \mathrm{m}$ after $1 \mathrm{~h}$ and 24 incubation, respectively (Figure S2, Supporting information).
In contrast, the PEG-BPSi nanoparticles had excellent colloidal stability within $24 \mathrm{~h}$. The hydrophilic PEG coating inhibits effectively the aggregation of the nanoparticles and enhances the colloidal stability. The functional groups on the BPSi nanoparticles were further analyzed with Fourier transform infrared (FT-IR) spectroscopy. The absorbance peak at $1730 \mathrm{~cm}^{-1}$, attributed to the $-\mathrm{C}=\mathrm{O}$ stretching in the 2.0 kDa PEG-silane, was observed after the dual-PEGylation (Figure S3, Supporting information). ${ }^{24}$ In addition, intensive peaks of $\mathrm{C}-\mathrm{H}$ stretching in the range of $2800-3000 \mathrm{~cm}^{-1}$ also appeared in the spectrum of PEG-BPSi. ${ }^{31}$ Based on the thermogravimetric analysis (TGA) measurements, about $10.8 \%$ of PEGs were grafted on the surface of PEG-BPSi (Figure S4, Supporting information). Due to the surface PEGylation, the $\zeta$-potential of the nanoparticles was changed from -24 to $+2.0 \mathrm{mV}$ (Figure S5, Supporting information). The surface charge close to neutral is beneficial to biological stability for a long systemic circulation. ${ }^{32}$ All of these evidences indicated that the PEGs were successfully grafted on the surface of BPSi nanoparticles. The biocompatibility of the nanoparticles was evaluated with the noncancerous cells of mouse embryonic fibroblasts and macrophages RAW 264.7 in vitro (Figure S6, Supporting Information). Generally, the BPSi nanoparticles did not show a cytotoxicity effect on either the embryonic fibroblasts or macrophages after $24 \mathrm{~h}$ of exposure if the nanoparticle concentration was below $0.2 \mathrm{mg} / \mathrm{mL}$. The BPSi nanoparticles showed moderate cytotoxicity with both types of cells when the concentrations were higher than 0.5 $\mathrm{mg} / \mathrm{mL}$. However, the biocompatibility of the BPSi nanoparticles was significantly enhanced because of the surface PEGylation. The PEG-BPSi nanoparticles did not exhibit cytotoxicity toward embryonic fibroblasts and macrophages even at a concentration of $0.5 \mathrm{mg} / \mathrm{mL}$, indicating that the nanoparticles had better compatibility as compared with other inorganic imaging contrast agents like gold and carbon nanotubes. $^{33}$

In the present study, the Au nanoparticles were used as the reference material because (1) they have been widely studied as contrast agents in PAT, ${ }^{10}$ (2) the BPSi nanoparticles have a particle diameter similar to that of Au nanoparticles, and (3) the light-absorption peaks of both BPSi and Au nanoparticles are close to the wavelength of LED $(617 \mathrm{~nm})$ in the photoacoustic imaging system. The mean hydrodynamic diameters of the PEG-BPSi and PEG-Au nanoparticles were 174 and $165 \mathrm{~nm}$ in deionized $\mathrm{H}_{2} \mathrm{O}$, which were consistent with the results observed with transmission electron 

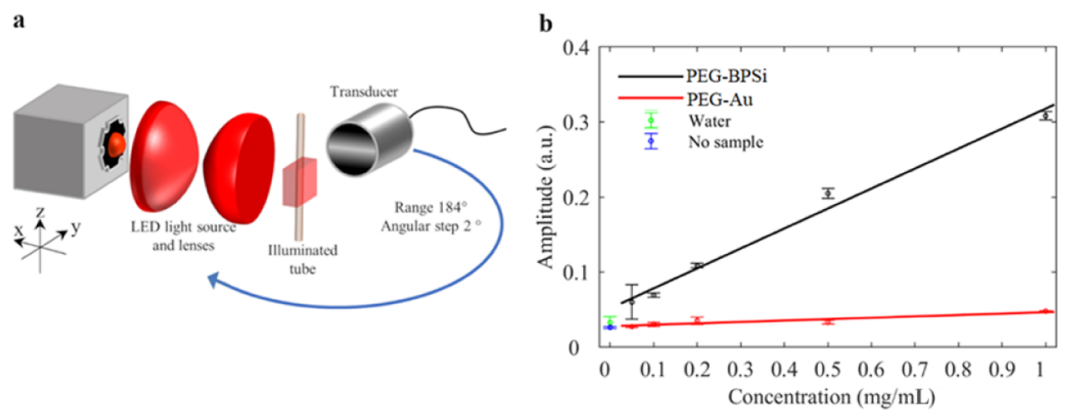

Figure 2. (a) Principle of the photoacoustic signal level measurement of nanoparticles. (b) Measured photoacoustic amplitudes (mean \pm SD, $n=$ 3 ) as a function of concentration for nanoparticles and water.

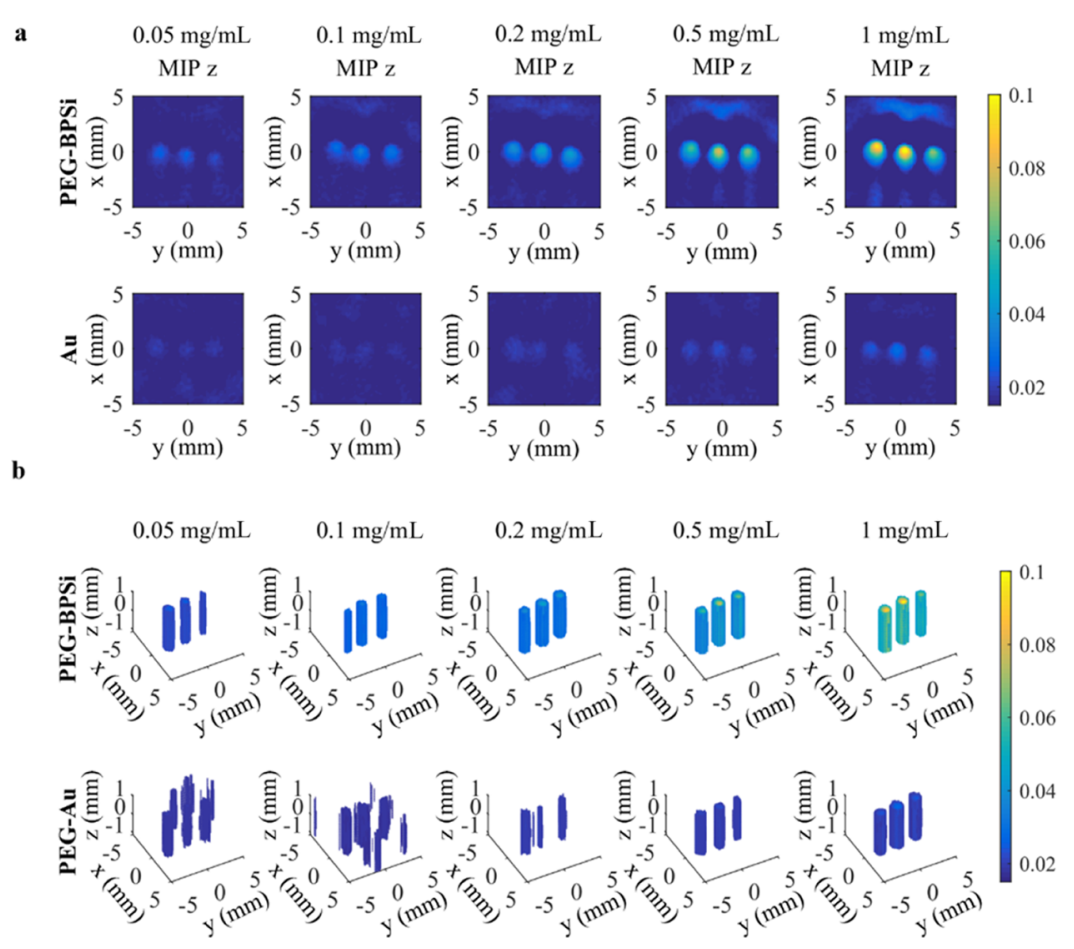

Figure 3. Reconstructions of three tubes having different concentrations $(0.05,0.1,0.2,0.5$, or $1 \mathrm{mg} / \mathrm{mL}$ ) of nanoparticles (PEG-BPSi or PEG$\mathrm{Au})$. The reconstructions visualize (a) maximum-intensity projections (MIP) in the $z$-direction ( $x y$-plane) and (b) volumetric images. The angular step in the measurements was $1^{\circ}$.

microscopy (TEM) (Figure S7, Supporting Information). The PEG-BPSi nanoparticles presented an irregular shape, while the shape of the PEG-Au nanoparticles was spherical. Figure 1a shows UV-vis absorption spectra of PEG-BPSi and PEG$\mathrm{Au}$ nanoparticles in an aqueous solution with a concentration of $0.1 \mathrm{mg} / \mathrm{mL}$. The BPSi and $\mathrm{Au}$ nanoparticles have lightabsorbance peaks at 550 and $629 \mathrm{~nm}$, respectively. In the present study, the light source in the PAT system has a wavelength of $617 \mathrm{~nm}$, which is close to the peak absorbance of BPSi and Au nanoparticles. The mass extinction coefficients of PEG-BPSi and PEG-Au at $617 \mathrm{~nm}$ were 24.3 and $5.6 \mathrm{~L}$ $\mathrm{g}^{-1} \mathrm{~cm}^{-1}$ based on the Lambert-Beer law, ${ }^{34}$ respectively. The BPSi nanoparticles have a low level of $\mathrm{Na}$ impurity $(0.6 \%)$, lowering the bandgap down to $1.34 \mathrm{eV}$, which corresponds to the wavelength of $925 \mathrm{~nm} .^{22}$ This improves the light absorbance of BPSi at the wavelengths used in the present study. The strong light absorption of PEG-BPSi indicates that the nanoparticles have great potential to be applied as imaging contrasts in PAT where the produced image corresponds to the reconstructed initial pressure $\mathrm{p}_{0}$ caused by the photo- acoustic effect. This pressure is directly dependent on light absorption through the relation described by

$$
p_{0}=\Gamma \mu_{\mathrm{a}} \Phi\left(\mu_{\mathrm{a}}, \mu_{\mathrm{s}}\right)
$$

where $\mu_{\mathrm{a}}$ is the absorption coefficient, and $\Phi\left(\mu_{\mathrm{a}}, \mu_{\mathrm{s}}\right)$ is the light fluence that depends on the intensity of the light source and absorption and scattering $\mu_{\text {s }}$ parameters, and can be solved using a light transport model such as the radiative transfer equation..$^{3}$ Further, $\Gamma$ is the Grüneisen parameter that is used to identify photoacoustic efficiency.

To test and compare the heating tendency of nanoparticles, the temperature rise after $5 \mathrm{~min}$ of LED illumination was measured using a thermocouple immersed in the sample dispersion. The temperature increased as a function of the concentration (Figure $1 \mathrm{~b}$ ), and the highest temperature rise was measured with the concentration of $0.5 \mathrm{mg} / \mathrm{mL}(19.2 \pm$ $\left.0.4{ }^{\circ} \mathrm{C}\right)$, followed by the concentration of $1 \mathrm{mg} / \mathrm{mL}(19.0 \pm$ $0.2{ }^{\circ} \mathrm{C}$ ). The increased values of temperature are basically identical, indicating heating saturation above the concentration of $0.5 \mathrm{mg} / \mathrm{mL}$ due to the long optical path inside the 


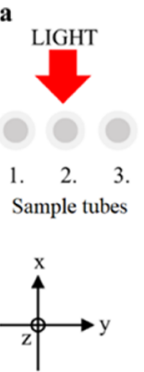

b
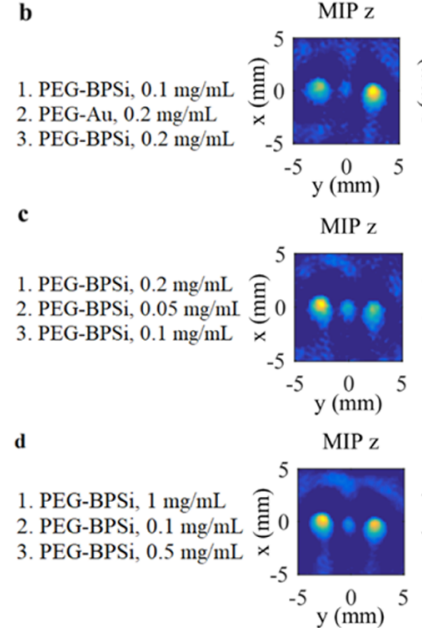

MIP x
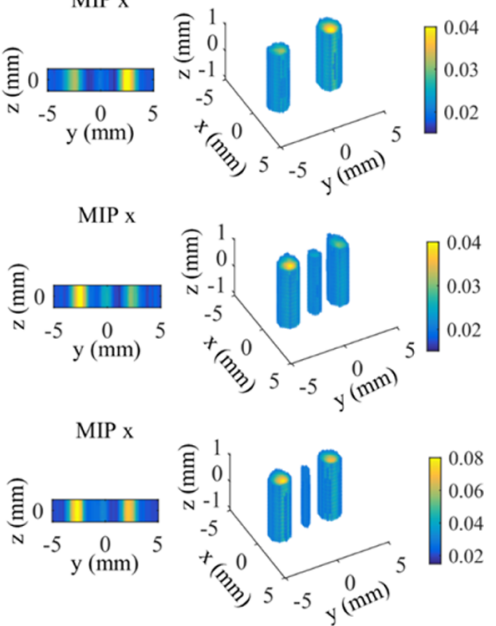

Figure 4. Reconstructions of three tubes having different nanoparticles or concentrations: (a) Illustration of three sample tubes illuminated with LED light. $(b-d)$ Comparison of PEG-BPSi and PEG-Au with different concentrations. The reconstructed images visualize the maximumintensity projections (MIPs) in the $z$-direction ( $x y$-plane) and $x$-direction ( $z y$-plane) and the volumetric images, respectively.

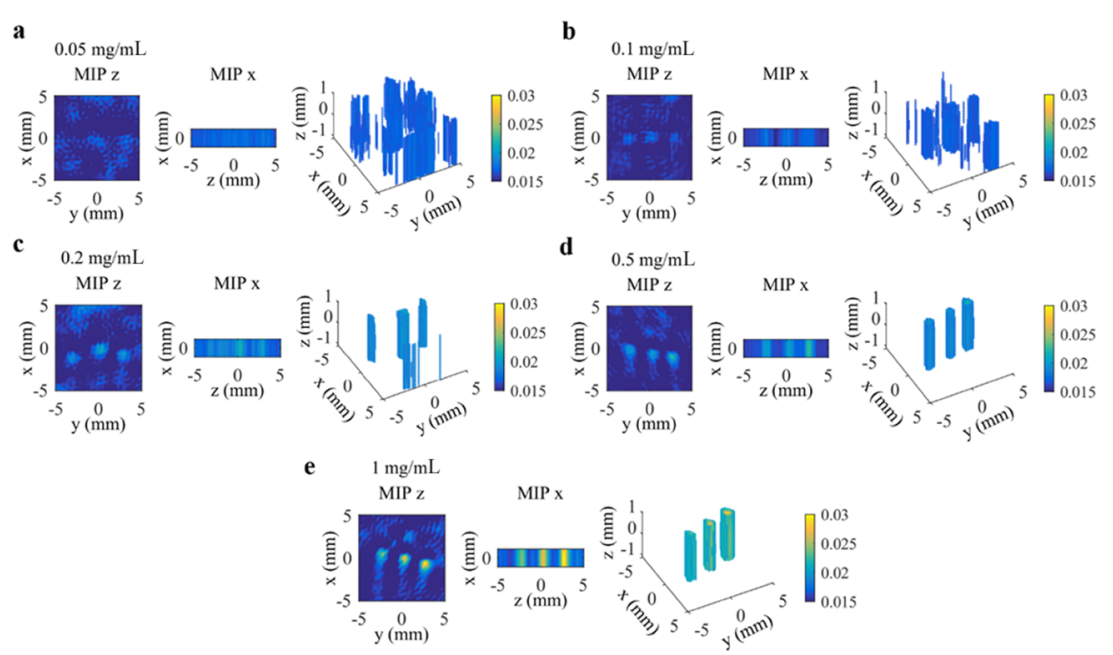

Figure 5. Reconstructions of three tubes placed inside a 4-6 mm-thick chicken tissue and having different PEG-BPSi concentrations: (a) 0.05 $\mathrm{mg} / \mathrm{mL}$, (b) $0.1 \mathrm{mg} / \mathrm{mL}$, (c) $0.2 \mathrm{mg} / \mathrm{mL}$, (d) $0.5 \mathrm{mg} / \mathrm{mL}$, and (e) $1 \mathrm{mg} / \mathrm{mL}$. The figures visualize the maximum-intensity projections (MIP) in the $z$-direction ( $x y$-plane) and $x$-direction $(z y$-plane), and volumetric images. Dimensions of chicken tissue samples were $1 \mathrm{~cm}(x$-direction), $3 \mathrm{~cm}(y$ direction), and $5 \mathrm{~cm}$ ( $z$-direction), that is, the reconstructions visualize the area and volume inside a tissue.

measurement vessel, resulting in nearly complete light absorption. With $0.05 \mathrm{mg} / \mathrm{ml}$ PEG-BPSi, the temperature rise $\left(9.5 \pm 0.1{ }^{\circ} \mathrm{C}\right)$ was comparable to that generated by a 10 times higher concentration $(0.5 \mathrm{mg} / \mathrm{mL})$ of $\mathrm{PEG}-\mathrm{Au}$ particles $\left(9.6 \pm 0.3{ }^{\circ} \mathrm{C}\right)$. In a sample of blank water, the temperature elevated by less than $1{ }^{\circ} \mathrm{C}$. Based on the temperature measurements, the PEG-BPSi particles generated roughly twice as high temperatures compared to the PEG-Au particles with the same concentration. When the LED power was increased from 1 to $2 \mathrm{~W}$ and the $0.05 \mathrm{mg} / \mathrm{mL}$ sample was exposed, the temperature rise was doubled to $19 \pm 0{ }^{\circ} \mathrm{C}$ (Figure S8, Supporting information). Accordingly, the LEDinduced temperature rise of the PEG-BPSi particles with different concentrations can be controlled by adjusting the LED power. Furthermore, it can be expected that the PEGBPSi particles can serve as good contrast agents for PAT where the initial acoustic pressure is generated by thermoelastic expansion.
To compare the photoacoustic signals from the PEG-BPSi and PEG-Au particles, single capillary tubes were filled with nanoparticle dispersions of different concentrations and measured with the LED-PAT configuration developed earlier (Figure 2a). ${ }^{24}$ The photoacoustic signal amplitude was calculated through a frequency spectrum analysis and averaged over the measurement angles (Figures S9-S11, Supporting information). The signal level from the PEG-BPSi particles was observed to follow a linear trend starting from $0.05 \mathrm{mg} /$ $\mathrm{mL}$ concentration (Figure $2 \mathrm{~b}$ ). The lowest concentration of $0.05 \mathrm{mg} / \mathrm{mL}$ was detectable, and the signal was above the levels of the background. The signal from the PEG-Au particles was barely above the background values but showed a slightly positive slope as a function of the concentration.

To detect and image nanoparticles through tomographic reconstructions, three identical capillary tubes were filled with different nanoparticle concentrations, measured using the PAT setup, and reconstructed applying the Bayesian approach (Figure 3). ${ }^{24,35}$ The reconstructed volumetric three-dimen- 
sional (3D) images and the maximum-intensity projections in the $z$-direction ( $x y$-plane) are shown in Figure $3 a, b$, respectively. Based on these experiments, the reconstructed maximum amplitude at the highest concentration $(1 \mathrm{mg} / \mathrm{mL})$ of PEG-Au was approximately at the same level as compared to the amplitude from the smallest concentration $(0.05 \mathrm{mg} /$ $\mathrm{mL}$ ) of PEG-BPSi. More specifically, the contrast value for the reconstructions was calculated from Figure 3a. The tube contrast using PEG-BPSi particles at $0.1 \mathrm{mg} / \mathrm{mL}$ was $0.84 \pm$ 0.12 and exceeded the contrast of PEG-Au particles at 10 times higher concentrations $(1 \mathrm{mg} / \mathrm{mL}: 0.60 \pm 0.15)$ (Table S1, Supporting information).

Next, the tubes were filled with dispersions having different nanoparticle concentrations and different particles (Figure 4). In the first experiment, the tubes contained both PEG-Au $(0.2$ $\mathrm{mg} / \mathrm{mL})$ and PEG-BPSi $(0.1$ and $0.2 \mathrm{mg} / \mathrm{mL})$ nanoparticles (Figure 4a). Both low and high PEG-BPSi concentrations could be detected from the background and discriminated from each other. The tube containing PEG-Au particles was not detectable. In the second experiment, the lowest concentration of PEG-BPSi particles $(0.05 \mathrm{mg} / \mathrm{mL})$ was placed between 0.1 and $0.2 \mathrm{mg} / \mathrm{mL}$ of PEG-BPSi (Figure $4 \mathrm{~b}$ ). The signal from the $0.05 \mathrm{mg} / \mathrm{mL}$ tube was small but detectable, while the signals from the two higher PEG-BPSi concentrations were similar to the measurement in Figure 4a. In the third experiment, $0.1 \mathrm{mg} / \mathrm{mL}$ PEG-BPSi concentration was placed between the tubes having the highest PEG-BPSi concentrations $(0.5$ and $1 \mathrm{mg} / \mathrm{mL}$ ) (Figure $4 \mathrm{c}$ ). The $0.1 \mathrm{mg} /$ $\mathrm{mL}$ tube was detectable between the high contrast tubes and had an amplitude similar to that in Figure $4 a, b$, indicating systematic detection and a repeatable signal level.

To test the imaging contrast for LED-PAT ex vivo, tubes filled with different nanoparticle dispersions were imaged inside chicken tissue (Figure 5). The capillary tubes were placed at the center of $1 \mathrm{~cm}$-thick ( $x$-direction) tissue blocks so that the tubes were approximately $4-6 \mathrm{~mm}$ deep in the tissue. The height ( $z$-direction) and width ( $y$-direction) of these blocks were 5 and $3 \mathrm{~cm}$, respectively. The qualitative estimate for a minimum detectable concentration, so that all three tubes were clearly distinguishable in all three repeats, was $0.2 \mathrm{mg} /$ $\mathrm{mL}$. The tubes with $0.1 \mathrm{mg} / \mathrm{mL}$ nanoparticles were still detectable in most repeated experiments (Figures 5 and S12 and S13, Supporting information). In addition to heterogeneities of chicken tissue pieces, the spacing between the tubes and the tube orientation varied as the flexible tubes were misaligned when they were pushed through the tissue block, causing variations of the received acoustic signal in the LEDPAT experiment.

\section{CONCLUSIONS}

The feasibility of black porous silicon nanoparticles as a contrast agent for 3D PAT was shown. They were observed to provide excellent photoacoustic contrast that was significantly stronger than that of the reference $\mathrm{Au}$ nanoparticles. More precisely, the PEG-BPSi particles were found to provide a higher contrast at $0.1 \mathrm{mg} / \mathrm{mL}$ than the PEG-Au particles at 1 $\mathrm{mg} / \mathrm{mL}$ in the LED-PAT system. Furthermore, submillimeter absorbers with a concentration of $0.2 \mathrm{mg} / \mathrm{mL}$ PEG-BPSi could be clearly observed inside approximately $5 \mathrm{~mm}$-thick chicken tissue ex vivo. This indicates that the BPSi nanoparticles can be utilized as efficient contrast agents for PAT, where they could be used, for example, to increase the sensitivity of the technique for imaging certain targeted tissue types and to increase the imaging depth. This can be especially useful in LED-based systems with low light intensity. Overall, versatile LED illumination combined with the highly efficient contrast agent of BPSi nanoparticles can offer an alternative for large solid-state lasers for certain applications of biomedical imaging: for example, the diagnosis of skin cancer, subcutaneous tumors such as breast cancer, and ocular choroidal melanoma.

\section{EXPERIMENTAL SECTION}

The BPSi nanoparticles were prepared via the reaction between $\mathrm{NaSi}$ and $\mathrm{NH}_{4} \mathrm{Br}$ at $250{ }^{\circ} \mathrm{C}^{22}$ Subsequently, the BPSi nanoparticles were functionalized with 0.5 and $2.0 \mathrm{kDa}$ PEG-silanes to improve biocompatibility. More experimental details are provided in the Supporting Information.

\section{ASSOCIATED CONTENT}

\section{(s) Supporting Information}

The Supporting Information is available free of charge at https://pubs.acs.org/doi/10.1021/acsami.9b18844.

Experimental materials and methods; results of the Raman spectrum; colloidal stability, FT-IR spectra, TGA curves, $\zeta$-potential, particle size distribution, TEM, biocompatibility, and temperature rise graphs; the repeated photoacoustic tomography measurements of chicken tissue samples; the sinograms for nanoparticles, water, and the reference measurement using $0.5 \%$ ink solution; frequency spectra as a function of the measurement angle calculated using the waveforms; and image contrast values (PDF)

\section{AUTHOR INFORMATION}

\section{Corresponding Author}

Vesa-Pekka Lehto - Department of Applied Physics, University of Eastern Finland, Kuopio 70211, Finland; (1) orcid.org/ 0000-0001-8153-1070; Email: vesa-pekka.lehto@uef.fi

\section{Authors}

Wujun Xu - Department of Applied Physics, University of Eastern Finland, Kuopio 70211, Finland; 이잉.org/00000002-3177-4709

Jarkko Leskinen - Department of Applied Physics, University of Eastern Finland, Kuopio 70211, Finland

Jenni Tick - Department of Applied Physics, University of Eastern Finland, Kuopio 70211, Finland

Emilia Happonen - Department of Applied Physics, University of Eastern Finland, Kuopio 70211, Finland

Tanja Tarvainen - Department of Applied Physics, University of Eastern Finland, Kuopio 70211, Finland

Complete contact information is available at:

https://pubs.acs.org/10.1021/acsami.9b18844

\section{Notes}

The authors declare no competing financial interest.

\section{ACKNOWLEDGMENTS}

W.X. thanks Mervi Hyvönen (University of Eastern Finland) for kindly providing mouse embryonic fibroblasts in cell tests. T.T. would like to dedicate this paper to the memory of her student Gisela Miettinen. This work was supported by the Academy of Finland (projects 314411, 314412, and 312342 
(Centre of Excellence in Inverse Modelling and Imaging)) and Jane and Aatos Erkko Foundation.

\section{REFERENCES}

(1) Kim, H.; Lee, H.; Moon, H.; Kang, J.; Jang, Y.; Kim, D.; Kim, J.; Huynh, E.; Zheng, G.; Kim, H.; Chang, J. Resonance-Based Frequency-Selective Amplification for Increased Photoacoustic Imaging Sensitivity. ACS Photonics 2019, 6, 2268-2276.

(2) Wang, L. V.; Yao, J. A Practical Guide to Photoacoustic Tomography in the Life Sciences. Nat. Methods 2016, 13, 627-638.

(3) Choi, W.; Park, E. Y.; Jeon, S.; Kim, C. Clinical Photoacoustic Imaging Platforms. Biomed. Eng. Lett. 2018, 8, 139-155.

(4) Lee, D.; Beack, S.; Yoo, J.; Kim, S.; Lee, C.; Kwon, W.; Hahn, S.; Kim, C. In Vivo Photoacoustic Imaging of Livers Using Biodegradable Hyaluronic Acid-Conjugated Silica Nanoparticles. Adv. Funct. Mater. 2018, 28, No. 1800941.

(5) Upputuri, P.; Pramanik, M. Fast Photoacoustic Imaging Systems Using Pulsed Laser Diodes: a Review. Biomed. Eng. Lett. 2018, 8, 167-181.

(6) Lin, X.; Liu, C.; Sheng, Z.; Gong, X.; Song, L.; Zhang, R.; Zheng, H.; Sun, M. Highly Sensitive Fluorescence and Photoacoustic Detection of Metastatic Breast Cancer in Mice Using Dual-Modal Nanoprobes. ACS Appl. Mater. Interfaces 2018, 10, 26064-26074.

(7) Liu, Y.; Liu, H.; Yan, H.; Liu, Y.; Zhang, J.; Shan, W.; Lai, P.; Li, H.; Ren, L.; Li, Z.; Nie, L. Aggregation-Induced Absorption Enhancement for Deep Near-Infrared II Photoacoustic Imaging of Brain Gliomas In Vivo. Adv. Sci. 2019, 6, No. 1801615.

(8) Liu, Y.; Yang, Y.; Sun, M.; Cui, M.; Fu, Y.; Lin, Y.; Li, Z.; Nie, L. Highly Specific Noninvasive Photoacoustic and Positron Emission Tomography of Brain Plaque with Functionalized Croconium Dye Labeled by a Radiotracer. Chem. Sci. 2017, 8, 2710-2716.

(9) Liu, Y.; Lv, X.; Liu, H.; Zhou, Z.; Huang, J.; Lei, S.; Cai, S.; Chen, Z.; Guo, Y.; Chen, Z.; Zhou, X.; Nie, L. Porous Gold Nanocluster-Decorated Manganese Monoxide Nanocomposites for Microenvironment-Activatable MR/Photoacoustic/CT Tumor Imaging. Nanoscale 2018, 10, 3631-3638.

(10) Tian, C.; Qian, W.; Shao, X.; Xie, Z.; Cheng, X.; Liu, S.; Cheng, Q.; Liu, B.; Wan, X. Plasmonic Nanoparticles with Quantitatively Controlled Bioconjugation for Photoacoustic Imaging of Live Cancer Cells. Adv. Sci. 2016, 3, No. 1600237.

(11) Chen, Y. S.; Frey, W.; Kim, S.; Kruizinga, P.; Homan, K.; Emelianov, S. Silica-Coated Gold Nanorods as Photoacoustic Signal Nanoamplifiers. Nano Lett. 2011, 11, 348-354.

(12) De la Zerda, A.; Liu, Z.; Bodapati, S.; Teed, R.; Vaithilingam, S.; Khuri-Yakub, B. T.; Chen, X.; Dai, H.; Gambhir, S. S. Ultrahigh Sensitivity Carbon Nanotube Agents for Photoacoustic Molecular Imaging in Living Mice. Nano Lett. 2010, 10, 2168-2172.

(13) Ku, G.; Zhou, M.; Song, S.; Huang, Q.; Hazle, J.; Li, C. Copper Sulfide Nanoparticles As a New Class of Photoacoustic Contrast Agent for Deep Tissue Imaging at $1064 \mathrm{~nm}$. ACS Nano 2012, 6, 7489-7496.

(14) Santiesteban, D. Y.; Dumani, D. S.; Profili, D.; Emelianov, S. Y. Copper Sulfide Perfluorocarbon Nanodroplets as Clinically Relevant Photoacoustic/Ultrasound Imaging Agents. Nano Lett. 2017, 17, 5984-5989.

(15) Nie, L.; Chen, X. Structural and Functional Photoacoustic Molecular Tomography Aided by Emerging Contrast Agents. Chem. Soc. Rev. 2014, 43, 7132-7170.

(16) Singh, R. K.; Patel, K. D.; Leong, K. W.; Kim, H.-W. Progress in Nanotheranostics Based on Mesoporous Silica Nanomaterial Platforms. ACS Appl. Mater. Interfaces 2017, 9, 10309-10337.

(17) Rytkönen, J.; Arukuusk, P.; Xu, W.; Kurrikoff, K.; Langel, Ü.; Lehto, V.-P.; Närvänen, A. Porous Silicon-Cell Penetrating Peptide Hybrid Nanocarrier for Intracellular Delivery of Oligonucleotides. Mol. Pharmaceutics 2014, 11, 382-390.

(18) Park, J. H.; Gu, L.; von Maltzahn, G.; Ruoslahti, E.; Bhatia, S. N.; Sailor, M. J. Biodegradable Luminescent Porous Silicon Nanoparticles for In Vivo Applications. Nat. Mater. 2009, 8, 331-336.
(19) Tamarov, K.; Sviridov, A.; Xu, W.; Malo, M.; Andreev, V.; Timoshenko, V.; Lehto, V.-P. Nano Air Seeds Trapped in Mesoporous Janus Nanoparticles Facilitate Cavitation and Enhance Ultrasound Imaging. ACS Appl. Mater. Interfaces 2017, 9, 3523435243.

(20) Kang, J.; Kim, D.; Wang, J.; Han, Y.; Zuidema, J. M.; Hariri, A.; Park, J.-H.; Jokerst, J. V.; Sailor, M. J. Enhanced Performance of a Molecular Photoacoustic Imaging Agent by Encapsulation in Mesoporous Silicon Nanoparticles. Adv. Mater. 2018, 30, No. 1800512.

(21) Zhang, J.; Zhang, J.; Li, W.; Chen, R.; Zhang, Z.; Zhang, W.; Tang, Y.; Chen, X.; Liu, G.; Lee, C.-S. Degradable Hollow Mesoporous Silicon/Carbon Nanoparticles for Photoacoustic Imaging-Guided Highly Effective Chemo-Thermal Tumor Therapy in Vitro and in Vivo. Theranostics 2017, 7, 3007-3020.

(22) Xu, W.; Tamarov, K.; Fan, L.; Granroth, S.; Rantanen, J.; Nissinen, T.; Peräniemi, S.; Uski, O.; Hirvonen, M.-R.; Lehto, V.-P. Scalable Synthesis of Biodegradable Black Mesoporous Silicon Nanoparticles for Highly Efficient Photothermal Therapy. ACS Appl. Mater. Interfaces 2018, 10, 23529-23538.

(23) Xi, L.; Grobmyer, S. R.; Zhou, G.; Qian, W.; Yang, L.; Jiang, H. Molecular Photoacoustic Tomography of Breast Cancer Using Receptor Targeted Magnetic Iron Oxide Nanoparticles as Contrast Agents. J. Biophotonics 2014, 7, 401-409.

(24) Näkki, S.; Rytkönen, J.; Ek, P.; Zhang, H.; Santos, H. A.; Närvänen, A.; Xu, W.; Lehto, V.-P.; et al. Improved stability and biocompatibility of nanostructured silicon drug carrier for intravenous administration. Acta Biomater. 2015, 13, 207-2015.

(25) Leskinen, J.; Pulkkinen, A.; Tick, J.; Tarvainen, T. Photoacoustic Tomography Setup Using LED Illumination, Proc. SPIE 11077, OptoAcoustic Methods Appl. Biophotonics IV, 2019, V, 110770Q.

(26) Yao, Q.; Ding, Y.; Liu, G.; Zeng, L. Low-Cost Photoacoustic Imaging Systems Based on Laser Diode and Light-Emitting Diode Excitation. J. Innovative Opt. Health Sci. 2017, 10, No. 1730003.

(27) Dai, X.; Yang, H.; Jiang, H. In Vivo Photoacoustic Imaging of Vasculature With a Low-Cost Miniature Light Emitting Diode Excitation. Opt. Lett. 2017, 42, 1456-1459.

(28) Hariri, A.; Lemaster, J.; Wang, J.; Jeevarathinam, A.; Chao, D.; Jokerst, J. The Characterization of an Economic and Portable LEDbased Photoacoustic Imaging System to Facilitate Molecular Imaging. Photoacoustics 2018, 9, 10-20.

(29) Erfanzadeh, M.; Zhu, Q. Photoacoustic Imaging with Low-cost Sources; A Review. Photoacoustics 2019, 14, 1-11.

(30) Cheng, G. X.; Xia, H.; Chen, K. J.; Zhang, W.; Zhang, X. K. Raman Measurement of the Grain Size for Silicon Crystallites. Phys. Status Solidi A 1990, 118, K51-K54.

(31) Xu, W.; Rytkönen, J.; Rönkkö, S.; Nissinen, T.; Kinnunen, T.; Suvanto, M.; Närvänen, A.; Lehto, V.-P. A Nano-Stopper Approach to Selectively Engineer the Surfaces of Mesoporous Silicon. Chem. Mater. 2014, 26, 6734-6742.

(32) Xiao, K.; Li, Y.; Luo, J.; Lee, J. S.; Xiao, W.; Gonik, A. M.; Agarwal, R. G.; Lam, K. S. The Effect of Surface Charge on In Vivo Biodistribution of PEG-Oligocholic Acid Based Micellar Nanoparticles. Biomaterials 2011, 32, 3435-3446.

(33) Mannerström, M.; Zou, J.; Toimela, T.; Pyykkö, I.; Heinonen, T. The applicability of Conventional Cytotoxicity Assays to Predict Safety/Toxicity of Mesoporous Silica Nanoparticles, Silver and Gold nanoparticles and Multi-walled carbon nanotubes. Toxicol. In Vitro 2016, 37, 113-120.

(34) Xuan, J.; Wang, Z.; Chen, Y.; Liang, D.; Cheng, L.; Yang, X.; Liu, Z.; Ma, R.; Sasaki, T.; Geng, F. Organic-Base-Driven Intercalation and Delamination for the Production of Functionalized Titanium Carbide Nanosheets with Superior Photothermal Therapeutic Performance. Angew. Chem., Int. Ed. 2016, 55, 14569-14574.

(35) Tick, J.; Pulkkinen, A.; Tarvainen, T. Image Reconstruction with Uncertainty Quantification in Photoacoustic Tomography. J. Acoust. Soc. Am. 2016, 139, 1951-1961. 